\title{
Property enhancement of healable supramolecular polyurethanes
}

\section{Article}

\section{Accepted Version}

Creative Commons: Attribution-Noncommercial-No Derivative Works 4.0

Salimi, S., Hart, L. R., Feula, A., Hermida-Merino, D., Touré, A. B. R., Kabova, E. A., Ruiz-Cantu, L., Irvine, D. J., Wildman, R., Shankland, K. and Hayes, W. (2019) Property enhancement of healable supramolecular polyurethanes. European Polymer Journal, 118. pp. 88-96. ISSN 0014-3057 doi: https://doi.org/10.1016/j.eurpolymj.2019.05.042 Available at https://centaur.reading.ac.uk/83829/

It is advisable to refer to the publisher's version if you intend to cite from the work. See Guidance on citing.

To link to this article DOI: http://dx.doi.org/10.1016/j.eurpolymj.2019.05.042

Publisher: Elsevier

All outputs in CentAUR are protected by Intellectual Property Rights law, including copyright law. Copyright and IPR is retained by the creators or other copyright holders. Terms and conditions for use of this material are defined in the End User Agreement.

\section{www.reading.ac.uk/centaur}

\section{CentAUR}


Central Archive at the University of Reading

Reading's research outputs online 


\title{
Property Enhancement of Healable Supramolecular Polyurethanes
}

S. Salimi, ${ }^{a}$ L.R. Hart, ${ }^{a}$ A. Feula, ${ }^{a}$ D. Hermida-Merino, ${ }^{\mathrm{b}}$ A. B. R. Touré, ${ }^{\mathrm{c}}$ E. A. Kabova, ${ }^{\mathrm{d}}$. L. RuizCantu, ${ }^{\mathrm{c}}$ D. J. Irvine, ${ }^{\mathrm{c}}$ R. Wildman, ${ }^{\mathrm{c}}$ K. Shankland ${ }^{\mathrm{d}}$ and W. Hayes*a

a Department of Chemistry, University of Reading, Whiteknights, Reading, RG6 6AD, UK, Email: w.c.hayes@ reading.ac.uk.

${ }^{\mathrm{b}}$ Netherlands Organisation for Scientific Research (NWO), DUBBLE @ ESRF, The European Synchrotron Radiation Facility, 71 Avenue des Martyrs, 38000, Grenoble, France.

${ }^{c}$ Faculty of Engineering, The University of Nottingham, University Park, Nottingham, NG7 2RD, UK

d School of Pharmacy, University of Reading, Whiteknights, Reading, RG6 6AD, UK

\begin{abstract}
Low molecular weight additives which can cooperatively self-assemble with supramolecular polyurethanes via complementary hydrogen bonding interactions offer an attractive route to enhancing the properties of addressable polymer networks. Here, we present the design, synthesis, characterisation and mechanical properties of a series of supramolecular polyurethanes with varied loadings of a low molecular weight bis-urea additive. These additives are able to self-assemble with analogous recognition motifs within the supramolecular polyurethanes to form polar 'hard' domains, promoting phase separation within the material and, crucially, increasing the strength of the polymer network. In addition, the bis-urea additive is a by-product within the polymerisation and thus can be synthesised in situ, without the need for complex purification or blending. The mechanical properties of these reinforced polymers were enhanced when compared to the pristine supramolecular polyurethane alone, as a result of higher degrees of order within the polymer matrix. Furthermore, a formulation comprising the small molecule blended with the supramolecular polyurethane was produced to examine the effect of material preparation and filler dispersion within the polymer matrix. Interestingly, the mechanical performance of a blended material was diminished as a result of modest dispersion and incorporation within the polymer matrix. These findings thus demonstrate a facile, one-pot, method that does not require purification to produce reinforced supramolecular polyurethanes. This methodology may find use in industrial applications in which enhancements to the physical and mechanical properties can be easily achieved through the in situ synthesis of low molecular weight additives within the polymerisation.
\end{abstract}

Keywords: Supramolecular polymers, Polyurethanes, Additives, Fillers, Hydrogen bonding, Mechanical properties, Healable polymers. 


\section{Introduction}

Supramolecular polymers[1,2] are a class of stimuli responsive materials which are able to selfassemble into dynamic arrays as a result of highly directional and specific non-covalent interactions. These materials are comprised typically of low-molecular weight species which are able to form a pseudo high molecular weight polymer network with attractive physical properties. [3,4] The switchable nature of supramolecular polymers has been investigated for a wide range of potential applications including adhesives, surface-coatings and healable materials.[4-6] As a consequence of the highly addressable assembly motifs, supramolecular polymers offer a route to novel materials and properties which can be easily processed at relatively low temperatures.[7] Narrow processing windows are afforded through dissociation and subsequent reassociation of recognition motifs when subjected to external stimulus such as heat, light or pressure.[8-10] However, supramolecular polymers currently only have limited industrial use, especially in real-world structural applications, as the mechanical properties require further refinement.

One approach to enhancing the mechanical properties of supramolecular polymers is utilising additives which provide reinforcement of the polymer matrix.[11-15] Supramolecular polymer composites are known to improve the mechanical properties of the bulk polymer matrix. In an attempt to optimize the interface between additives and the polymer matrix, Bose et al. reported[16] a graphene oxide functionalized with PEEK to facilitate good dispersion within an epoxy matrix. Fox et al. reinforced a relatively weak but thermally responsive polymer supramolecular polymer blend with rigid, biosourced cellulose nanocrystals to afford healable nanocomposite materials.[17] The tensile modulus of the material increased from $8 \mathrm{MPa}$ to $261 \mathrm{MPa}$ as the proportion of filler increased up to $10 \mathrm{wt} \%$ and films were found to heal upon exposure to elevated temperatures of $85{ }^{\circ} \mathrm{C}$. In addition, supramolecular polymers that assemble via hydrogen bonding units with high association constant motifs such as ureidopyrimidinone have been shown to enhance the fracture toughening of carbon fiber composites whilst retaining the healing capability,[18] form robust composites[19,20] with nanosilica and reinforce a styrene-butadiene rubber.[21] In 2010, Shokrollahi et al. reported an approach in which both the polymer (functionalized polycaprolactone) and filler (hydroxyapatite) featured hydrogen bonding motifs to enhance the mechanical properties of the blend.[22] Additionally, specific molecular recognition between a healable supramolecular polymer blend material and functionalized gold nanoparticles featuring complementary surface groups has also been reported[23] by Vaiyapuri et al.. This healable composite highlighted the requirement for structural refinement of both the polymer and filler to realise a composite with efficient healing characteristics.

An alternative approach to creating reinforced materials is the addition of organic small molecules to the polymer matrix that structurally complement the receptor units within the phase separated bulk polymer.[24] Low molecular weight organic nucleating agents have previously been employed to great effect to induce phase separation and form hard domains within soft polymer matrices.[13,25,26] 
Furthermore, phase separation has been shown to increase the mechanical strength of the polymer network. In the light of the possible advantages of creating reinforced polymers from organic additives, in addition to our previous work on addressable and healing supramolecular polymers, [27-31] herein we report the facile route to enhancing the mechanical properties by reinforcing supramolecular polyurethanes with low molecular weight additives. A known[32] elastomeric supramolecular polyurethane (SPU) was doped with a complementary low molecular weight additive (LMWA) that can reinforce the hard segment by cooperatively forming hydrogen bonds to form supramolecular arrays with the polymer's hard segment. This is analogous to other approach reported in the literature in which hard segment content is increased through the incorporation of covalently bonded chain-extenders to enhance phase separation in polyurethanes.[33-37] Crucially, purification was not required to form the self-assembled polymer networks as the additive was formed in situ. The effect of increasing the weight percentage of the LMWA, and thus the relative hard domain content was studied systematically, and the material properties assessed. The polymer with the most promising mechanical properties was then selected and an analogous composition formulated by blending the constituent components from isolated intermediates at the equivalent weight ratio. The mechanical properties of the reinforced polyurethanes prepared in situ or formulated were then compared to assess the importance of polymer preparation. Finally, the healability of the reinforced materials were probed to assess the effect of the LMWA on the healing efficiency of the polymer matrix.

\section{Experimental}

\section{Materials and Instrumentation}

All reagents and solvents were purchased from Alfa Aesar, Fisher Scientific or Sigma Aldrich with the exception of Krasol HLBH-P 2000 [hydrogenated poly(butadiene)] which was supplied by TOTAL Cray Valley and used as received. Additionally, tetrahydrofuran (THF) was distilled from sodium and benzophenone prior to use.

${ }^{1} \mathrm{H}$ NMR spectroscopy (400 MHz) and ${ }^{13} \mathrm{C}$ NMR spectroscopy (100 MHz) were recorded with either a Bruker Nanobay 400, or Bruker DPX 400, using an appropriate deuterated solvent. Infrared spectra were collected using a Perkin-Elmer Spectrum 100 FTIR spectrometer with an ATR attachment. Gel permeation chromatography (GPC) analysis was obtained by an Agilent Technologies 1260 Infinity systems in THF and polystyrene standards were used for calibration. Differential Scanning Calorimetry (DSC) thermograms were obtained using a TA DSC Q2000 adapted with a TA Refrigerated Cooling System 90, using aluminium TA Tzero pans and lids. Thermal transitions were recorded using heating and cooling rates of $10{ }^{\circ} \mathrm{C} \mathrm{min}^{-1}$ and $20^{\circ} \mathrm{C} \mathrm{min}^{-1}$, respectively.

In order to cast films of the reinforced supramolecular polyurethanes (RSPUs), the THF volume was reduced to approximately $30 \mathrm{~mL}$ and the solution was poured into a $150 \mathrm{~mm} \times 150 \mathrm{~mm}$ PTFE mould. 
In the case of SPU 1, the purified solution was dissolved in THF $(30 \mathrm{~mL})$ and poured into a $150 \mathrm{~mm}$ $\times 150 \mathrm{~mm}$ PTFE mould. All films were left at room temperature for 2 hours before drying overnight in an oven at $70{ }^{\circ} \mathrm{C}$ under reduced pressure.

Tensile tests were carried out using AML instruments ${ }^{\mathrm{TM}}$ single column tensiometer. From each film 3 strips of $5 \mathrm{~mm} \times 40 \mathrm{~mm} \times 1 \mathrm{~mm}$ were cut and samples were placed between the grips of tensile instrument and pulled apart at a rate of $10 \mathrm{~mm} \mathrm{~min}^{-1}$. Rheology analysis was performed using an AntonPaar Physica MCR301 Rheometer, in oscillatory shear. For data collection strain was set to $0.1 \%$ and samples were heated at $2{ }^{\circ} \mathrm{C} / \mathrm{min}$. Small-Angle X-ray Scattering and Wide-Angle X-ray Scattering (SAXS/WAXS) experiments were performed on beamline BM26B (DUBBLE) at ESRF, Grenoble, France. Samples, as films, were placed in aluminium DSC pans with mica windows and mounted in a brass block for temperature control. The sample-to-detector (SAXS) distance was $3.9 \mathrm{~m}$, the sampleto-detector (WAXS) distance was $27.9 \mathrm{~cm}$ and the $\mathrm{X}$-ray energy was $12 \mathrm{keV}$. The $\mathrm{q}=4 \pi \sin \theta / \lambda$ range was calibrated using silver behenate. Data processing (background subtraction, radial averaging) was performed using Bubbles software. The powder X-ray diffraction pattern for LMWA 2 was collected on a Bruker D8 Advance operating in transmission capillary mode, whilst the data for films of RSPU15\% and RSPU-15\% (Blend) were collected on a Bruker D8 Advance operating in reflection flat-plate mode. All data were collected in the range $5-35^{\circ} 2 \theta$, with a step size $0.017^{\circ}$ and 2 seconds/step count time. Atomic force microscopy (AFM) measurements were conducted using a Dimension FastScan Bio AFM (Bruker Nano Surfaces Division) equipped with a motorised x-y-stage. Measurements were operated with a Nanoscope controller operated in a PeakForce Quantitative NanoMechanics (QNM) mode in air using a silicon tips with a resonant frequency of approximately $150 \mathrm{kHz}$ and a force constant of approximately $6 \mathrm{~N} / \mathrm{m}$ (RTESPA-150, Bruker Nano Inc.). Rectangular samples $(0.5 \times 0.5 \mathrm{~cm})$ were glued onto a glass slide and placed on the motorised stage. The microscope was focused onto each sample. The peak force set point, amplitude setpoint, drive amplitude and gains were adjusted during imaging. $5 \mu \mathrm{m} \times 5 \mu \mathrm{m}$ surface area scans were performed on the samples. Gwyddion software (version 2.22) was used for data analysis.

\section{Synthesis of Supramolecular Polyurethane 1}

Hydrogenated poly(butadiene) 3, molecular weight as supplied $=2000 \mathrm{~g} \mathrm{~mol}^{-1}$, was dried under vacuum in oven at $120{ }^{\circ} \mathrm{C}$ for 1 hour. In the bulk, hydrogenated poly(butadiene) $\mathbf{3}(10.00 \mathrm{~g}, 5 \mathrm{mmol}$ ) was mixed with 4,4'-MDI $4(2.50 \mathrm{~g}, 10 \mathrm{mmol})$ at $80^{\circ} \mathrm{C}$ under $\mathrm{N}_{2}$ for 3 hours with gentle stirring. The colourless pre-polymer 5 thus obtained was then dissolved in dry THF $(100 \mathrm{~mL})$ and allowed to cool to room temperature. 4-(2-Aminoethyl)morpholine $6(1.30 \mathrm{~g}, 10 \mathrm{mmol})$ was then added to the solution and this was maintained under reflux for 18 hours under $\mathrm{N}_{2}$. The solvent was then removed in vacuo and the supramolecular polymer 1 purified by dissolving in chloroform $(30 \mathrm{~mL})$ and repeated precipitation from 
methanol (× 3). $10.9 \mathrm{~g}, 80 \%$; IR (ATR) $\left(\mathrm{cm}^{-1}\right): 3311,2939,2921,2852,1651,1599,1537,1460,1413$, 1379, 1309, 1220, 1116, 1068; ${ }^{1} \mathrm{H}$ NMR $\left(\delta ; 400 \mathrm{MHz} ; \mathrm{CDCl}_{3}\right)$ 7.33-7.04 $(20 \mathrm{H}, m), 6.63-6.51(2 \mathrm{H}, \mathrm{br})$ 5.32-5.20 (2H, $b r), 4.19-4.12(4 \mathrm{H}, m), 3.89(4 \mathrm{H}, s), 3.64(4 \mathrm{H}, m), 3.33(2 \mathrm{H}, q, J=5.6), 2.50(2 \mathrm{H}, t, J=$ 6.0), $2.45(4 \mathrm{H}, m), 2.07-0.58(392 \mathrm{H}, m) ;{ }^{13} \mathrm{C} \mathrm{NMR}\left(\delta ; 100 \mathrm{MHz} ; \mathrm{CDCl}_{3}\right) 156.1,153.7,136.5,136.2$, 129.6, 129.4, 121.7, 118.9, 66.9, 57.8, 53.3, 40.6, 38.9, 37.9, 36.1, 33.4, 33.2, 30.7, 30.2, 29.8, 26.8, 25.9, 10.8; GPC (THF) $M_{\mathrm{n}}=9100 \mathrm{~g} \mathrm{~mol}^{-1}, M_{\mathrm{w}}=12500 \mathrm{~g} \mathrm{~mol}^{-1}, \mathrm{Ð}=1.37$.

\section{Synthesis of LMWA 2}

4,4'-MDI 4 (1.00 g, $4.0 \mathrm{mmol}$ ) and 4-(2-amino ethyl)morpholine (1.09 g, $8.4 \mathrm{mmol}) 6$ were dissolved in dry THF (40 mL) which was brought to and maintained under reflux under $\mathrm{N}_{2}$ for 3 hours. The resulting white solid was filtered and washed with THF to yield the title compound: $1.97 \mathrm{~g}, 99 \%$; $\mathrm{MP}_{(\mathrm{DSC})}=184-198^{\circ} \mathrm{C}$; IR (ATR) $\left(\mathrm{cm}^{-1}\right) 3302,1634,1575,1514,1242,1115,1007,913 .{ }^{1} \mathrm{H} \mathrm{NMR}$ $(\delta ; 400 \mathrm{MHz}$; DMSO-d 6 ): $8.54(2 \mathrm{H}, s), 7.28(4 \mathrm{H}, d, J=8.0 \mathrm{~Hz}), 7.06(4 \mathrm{H}, d, J=8.0 \mathrm{~Hz}), 6.03(2 \mathrm{H}, \mathrm{t} J$ $=4.0 \mathrm{~Hz}), 6.02(2 \mathrm{H}, t, J=8.0 \mathrm{~Hz}), 3.76(2 \mathrm{H}, s), 3.60(8 \mathrm{H}, t, J=4.0 \mathrm{~Hz}), 3.20(4 \mathrm{H}$, quart, $J=8.0 \mathrm{~Hz})$, $2.38(12 \mathrm{H}, m) ;{ }^{13} \mathrm{C}$ NMR $(\delta ; 100 \mathrm{MHz}$; DMSO-d 6$)$ 155.1, 138.4, 134.1, 128.7, 117.6, 66.1, 57.8, 53.2, 35.9; ESI-MS: calcd for $\mathrm{M}^{+}\left(\mathrm{C}_{27} \mathrm{H}_{39} \mathrm{~N}_{6} \mathrm{O}_{2}\right)$ : $511.3033 \mathrm{Da}, \mathrm{m} / \mathrm{z}$ found: $511.3017 \mathrm{Da}$.

\section{Synthesis of Reinforced Supramolecular Polyurethanes (RSPUs)}

All reinforced polyurethanes were synthesised following the procedure for SPU 1 but without purification; the masses and stoichiometry of each reagent used for each RSPU (prepared in situ) is shown in Tables 1 and 2. Full characterisation of the RSPUs can be found in the SI.

\begin{tabular}{cccc}
\hline Polyurethane & $\begin{array}{c}\text { Polymer (3) } \\
(\mathrm{g})\end{array}$ & $\begin{array}{c}4,4^{\prime}-\text { MDI (4) } \\
(\mathrm{g})\end{array}$ & $\begin{array}{c}\text { End-group (6) } \\
(\mathrm{g})\end{array}$ \\
\hline SPU 1 & 10.00 & 2.38 & 1.25 \\
RSPU-0\% & 10.00 & 2.38 & 1.25 \\
RSPU-8\% & 10.00 & 2.98 & 1.87 \\
RSPU-15\% & 10.00 & 3.57 & 2.50 \\
RSPU-21\% & 10.00 & 4.17 & 3.12 \\
\hline
\end{tabular}

Table 1: Mass of each reagent used in the synthesis of the supramolecular polymer composites.

\section{Preparation of Blended Reinforced Polyurethane (RSPU-15\% (Blend))}

SPU 1 (8.22 g, $85 \mathrm{wt} \%$ ) was dissolved in THF ( $40 \mathrm{~mL})$ followed by the addition of LMWA 2 (1.46 g, $15 \mathrm{wt} \%)$. The mixture was brought to and maintained under reflux for 24 hours before cooling to room 
temperature. The solvent volume was reduced, and the blended reinforced polymer was cast from solution.

\section{Results and Discussion}

The effective self-assembly of polyurethanes is a key parameter which defines the physical and mechanical characteristics of the material.[32] Organic, low molecular weight additives (LMWA) which can cooperatively add to the supramolecular array (Figure 1) may provide a route to reinforcing the polymer network through highly directional and specific hydrogen bonding interactions, as well as further improving the phase separation.[38-40] In addition, the highly directional interaction between polyurethanes and the LMWA may improve the dispersity of the additives within the polymer matrix. A combination of these factors may result an improvement to the polymers mechanical properties.

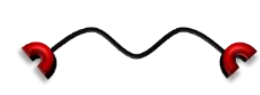

Polymer

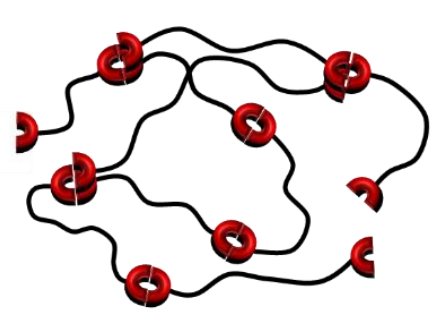

Supramolecular Polyurethane

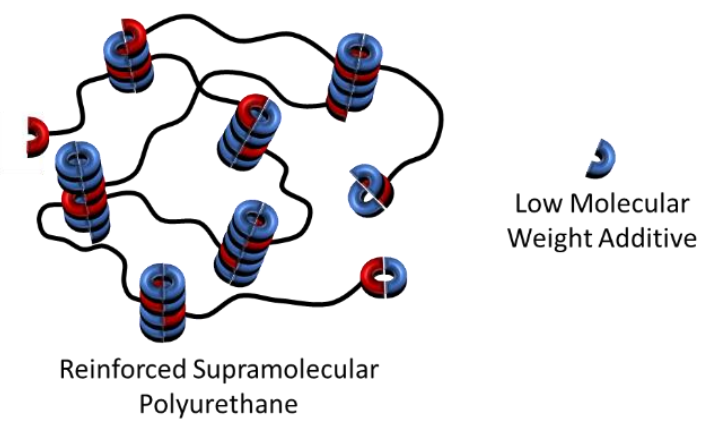

Polyurethane

Figure 1: An illustration of the self-assembly of the supramolecular polyurethane and cooperative self-assembly of the SPU with a low molecular weight additive to produce a reinforced supramoelcular polyurethane.

To achieve reinforced supramolecular polyurethanes (RSPUs), a facile one pot, two-step procedure was first employed to synthesise SPU 1.[32] Through careful synthetic design, the procedure was modified (Scheme 1) to prepare the LMWA 2 in situ as a by-product during the synthesis of SPU $\mathbf{1}$ and successfully yield a series of hydrogen bonding RSPUs. 


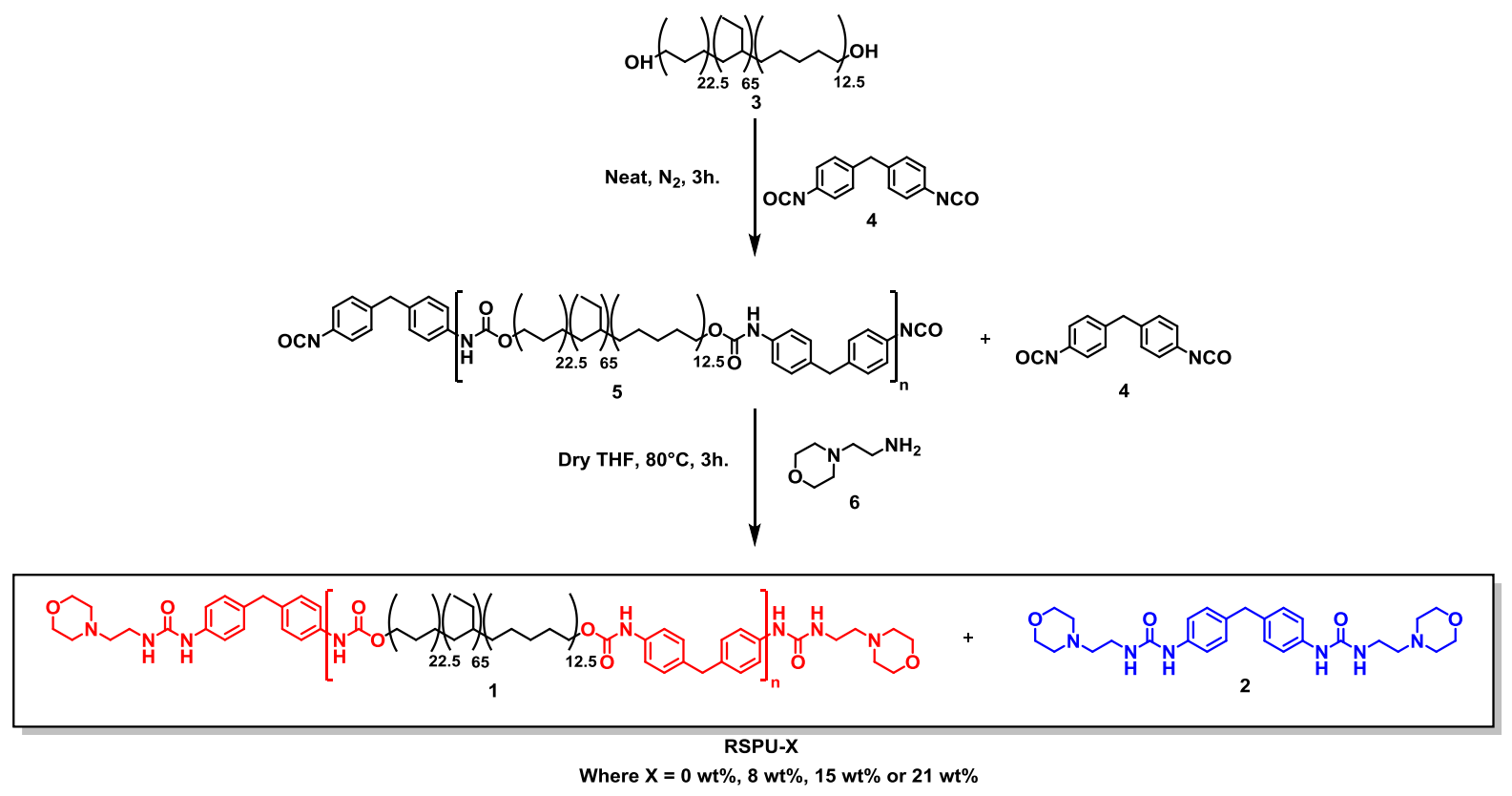

Scheme 1: Synthesis of the supramolecular polyurethane (SPU 1) and the in situ preparation of LMWA 2 to yield a reinforced supramolecular polyurethanes (RSPUs).

To synthesise the supramolecular polyurethanes, hydrogenated poly(butadiene) $\mathbf{3}$ (molecular weight as received $=2000 \mathrm{~g} \mathrm{~mol}^{-1}$ ) was first terminated with $4,4^{\prime}$-MDI 4 in the bulk to afford the pre-polymer $\mathbf{5}$, which was subsequently end-capped with the hydrogen-bonding moiety (4-(2-aminoethyl)morpholine) 6. As a control material, the SPU 1 was purified by repeated precipitations into methanol to remove any LMWA 2. The LMWA 2 content (produced in situ) for the reinforced supramolecular polyurethanes RSPUs was controlled by modifying the feed ratios (Table 2) of the diisocyanate $\mathbf{4}$ and the hydrogenbonding end-group 6 with respect to polymer 3 . The RSPU-0\% was produced using the same reagent stoichiometry as $\mathbf{1}$ but without purification, with the assumption that the polymerisation would continue to completion and LMWA 2 would not be afforded. Additionally, the absence of a purification step for all reinforced polymers allowed for the LMWA 2 to be retained in the bulk. A final composite was formulated by selecting the material with the most promising physical and mechanical characteristics and blending the appropriate weight ratios of SPU 1 and LMWA 2, after isolation to yield the equivalent reinforced polymer blend RSPU-15\% (Blend). 


\begin{tabular}{ccccc}
\hline Polyurethane & $\begin{array}{c}\text { Reagent Stoichiometry } \\
{[(\mathbf{3}): \mathbf{( 4 )}:(\mathbf{6})]}\end{array}$ & $\begin{array}{c}\text { Preparation } \\
\text { Method }\end{array}$ & $\begin{array}{c}\text { Molecular Weight } \\
\left(\boldsymbol{M}_{\mathbf{n}}, \mathbf{g} \mathbf{~ m o l}^{\mathbf{1}}\right)\end{array}$ & $\begin{array}{c}\text { Polydispersity } \\
(\mathbf{(})\end{array}$ \\
\hline SPU 1 & $1: 2: 2$ & One-pot \& purification & 9100 & 1.4 \\
RSPU-0\% & $1: 2: 2$ & One-pot & 8800 & 1.4 \\
RSPU-8\% & $1: 2.5: 3$ & One-pot & 7800 & 1.3 \\
RSPU-15\% & $1: 3: 4$ & One-pot & 7250 & 1.3 \\
RSPU-21\% & $1: 3.5: 5$ & One-pot & 7000 & 1.3 \\
RSPU-15\% (Blend) & $1: 3: 4$ & Blended & 8050 & \\
\hline
\end{tabular}

Table 2: The conditions and stoichiometry of starting materials used in the preparation of the SPU and RSPU samples, and the molecular weight data of the resulting polymers $\left(M_{\mathrm{n}}\right.$ of Krasol HLBH-P 2000 by GPC $=3400$ $\left.\mathrm{gmol}^{-1}\right)$. The percentage values are representative of the calculated percentage of LMWA 2 present in each polymer.

The successful synthesis of SPU 1 was first confirmed by ${ }^{1} \mathrm{H}$ NMR spectroscopy which revealed a resonance at $4.16 \mathrm{ppm}$, characteristic of methylene residue adjacent to newly formed urethanes in the polymer core. Furthermore, the installation of the hydrogen bonding motif to the pre-polymer $\mathbf{5}$ was confirmed by the triplet at $3.33 \mathrm{ppm}$, assigned to the methylene adjacent to the newly formed urea. ${ }^{13} \mathrm{C}$ NMR spectroscopy was also used to confirm the establishment of urea (156.2 ppm) and urethane (153.8 ppm) linkages, respectively in the supramolecular polymer. As an additional conformation of the formation of urethane/urea linkages in the supramolecular polyurethane 1, infra-red spectroscopy revealed the complete consumption of isocyanates functionalities as observed by the disappearance of the vibration at $2270 \mathrm{~cm}^{-1}$. Furthermore, new absorbances at $1642 \mathrm{~cm}^{-1}$ and $1706 \mathrm{~cm}^{-1}$ were attributed to the carbonyl stretches in the newly formed urethane/urea bonds, respectively.[35,41-43] Finally, GPC analysis was employed to confirm the extent of chain extension in the polyurethane, with an average of 2 hydrogenated poly(butadiene) residues per supramolecular polymer $\left(M_{\mathrm{n}}=9100 \mathrm{~g} \mathrm{~mol}^{-1}\right)$. This is in close agreement with integration analysis carried out by ${ }^{1} \mathrm{H}$ NMR spectroscopy. Spectroscopic data for all polymers reported in this paper can be found in the Supporting Information (SI, see Figures S1-S15). The low molecular weight additive 2 was prepared by mixing 4,4'-MDI 4 with the hydrogen bonding end-group 6 in dry THF and maintaining under reflux for 3 hours before isolating via filtration and subsequent washing with THF (see Figures S16-20).

The presence of additional LMWA 2, formed in situ in all RSPUs, was established by ${ }^{1} \mathrm{H}$ NMR spectroscopy (Figure S21).[44] An increase in additive 2 concentration was confirmed by comparing the integration of resonances from the polymer core $(4.14 \mathrm{ppm})$ relative to those from the methylene bridge of 4,4'-MDI residues at $3.89 \mathrm{ppm}$ - the ratio between polymer and small molecule could thus be determined (Figure S22A - solid bars). To further confirm this relationship, the integrals of the resonances arising from the polymer core (Figure S22A - hashed bars) were compared to those from the $\alpha$-protons to the urea $(3.33 \mathrm{ppm})$ of the hydrogen bonding end-group. Both analyses demonstrate an 
increase in the concentration of LMWA 2 in the reinforced supramolecular polyurethanes as the feed ratio was increased. In addition, GPC analysis (Table 2, Figure S14) of the reinforced supramolecular polyurethanes revealed an increase in the elution profile of the LMWA $2\left(M_{\mathrm{n}}=\sim 400 \mathrm{~g} \mathrm{~mol}^{-1}\right)$ component as the stoichiometry of the diisocyanate $\mathbf{4}$ and hydrogen bonding end-group $\mathbf{6}$ was increased with respect to hydrogenated poly(butadiene) $\mathbf{3}\left(M_{\mathrm{n}(\mathrm{GPC})}=3400 \mathrm{~g} \mathrm{~mol}^{-1}\right)$. The RSPU-0\% was shown to contain approximately $4.5 \%$ LMWA 2 by ${ }^{1} \mathrm{H}$ NMR spectroscopy and GPC analysis. Further analysis of the bimodal signal in the chromatogram attributed to the reinforced polymers revealed a decrease in molecular weight $\left(M_{\mathrm{n}}\right)$ with increased filler concentration $\left(\right.$ SPU1 $=9100 \mathrm{gmol}^{-1}$, RSPU-21\% $=7000$ $\mathrm{gmol}^{-1}$ ). In addition, a decrease in polydispersity index (SPU1 $Đ=1.4, \mathbf{R S P U - 2 1 \%} \mathrm{Ð}=1.2$ ) was also observed, indicating the extent of chain extension decreases with increased concentration of LMWA 2. The reduction in molecular weight was rationalised by considering the stoichiometry of the diisocyanate 4, which increases with respect to polymer 3 , thus reducing the probability for chain-extension.

The thermal properties of the supramolecular polyurethanes were also probed to assess the effect of the LMWA 2 on the supramolecular polymer array. The addition of LMWA 2 showed no effect on the glass transition temperature $\left(T_{\mathrm{g}}\right)$ of the soft phase of the RSPUs (Figure S15) when compared to that of SPU 1, which remained constant at $-47{ }^{\circ} \mathrm{C}$. By contrast, the melting point $\left(T_{\mathrm{m}}\right)$ was observed to increase in temperature and intensity in the RSPUs, from $140{ }^{\circ} \mathbf{C}$ (RSPU-0\%) to $171^{\circ} \mathrm{C}$ (RSPU-21\%) as a consequence of the LMWA 2 reinforcing the polyurethane network. Interestingly, the melting point of RSPU-15\% (Blend) exhibited a melting point at $191{ }^{\circ} \mathrm{C}$, which is approximately equivalent to that of LMWA 2 alone, revealing the additive is not able to fully penetrate the hydrogen bonding network of the polyurethane.

To assess the ability of the additive $\mathbf{2}$ to strengthen the polymer network, tensile testing was selected as the most appropriate method to evaluate the phase separated polymers. To facilitate this, drop-cast films were produced of the supramolecular polymer $\mathbf{1}$ and its reinforced analogues RSPUs. The polymer solutions were dried under vacuum at $70{ }^{\circ} \mathrm{C}$ to afford malleable and elastomeric films. The polymer films were then cut into strips (dimensions $=40 \mathrm{~mm} \times 5 \mathrm{~mm} \times 1 \mathrm{~mm}$ ) and elongated to break to assess their mechanical properties. The presence of the additive $\mathbf{2}$ (formed in situ) in the reinforced polymer improves the mechanical properties of the materials when compared to the supramolecular polymer alone (Figure 2). Indeed, a clear trend was observed between the weight percentage of LMWA and properties such as the modulus of toughness and ultimate tensile strength (Table 3). The polymer RSPU-21\% gave rise to the largest improvement in stiffness. A $3400 \%$ increase in the Young's modulus was observed (135.2 MPa), whilst the ultimate tensile strength increased by approximately $800 \%(2.5 \mathrm{MPa})$. However, a decrease in elasticity (strain at break $=3 \%)$ and modulus of toughness $(0.1 \mathrm{MPa})$ was evident as a result of the increased additive weight percentage, resulting in an extremely brittle material, possibly as a result of aggregation of the LMWA within the polymer matrix. Although the polymer RSPU-15\% gave rise to more modest mechanical properties (Young's modulus $=43.2$ 
$\mathrm{MPa}$, Ultimate tensile strength $=1.4 \mathrm{MPa}$, modulus of toughness $=0.49 \mathrm{MPa}$ ) the material was easy to handle and thus offered the best balance between mechanical properties and processability.

To identify if the method of formulation had a significant effect on the mechanical properties of the reinforced polyurethanes, a polymer blend was prepared by mixing the isolated SPU 1 with the LMWA 2 in solution before casting a polymer film. RSPU-15\% was selected as a candidate for this study as a result of the optimum mechanical properties and physical characteristics (Figure 2). To formulate the polymer blend, polyurethane $\mathbf{1}$ and bis-urea additive $\mathbf{2}$ were synthesised and isolated before refluxing the two components (15 wt\% of LMWA 2) in THF to afforded RSPU-15\% (Blend). The resulting solution was then drop-cast and the resulting film analysed by tensile testing. Surprisingly, a discernible difference was noted for the mechanical properties of RSPU-15\% and RSPU-15\% (Blend) (Figure 2). The reinforced polymer formulated by blending revealed a decrease in Young's modulus (18\% reduction), ultimate tensile strength (34\% weaker) whilst a small decrease in toughness (12\% less robust) was also observed which is essentially invariant when considering the error within the 3 repeat analyses. Interestingly, an increase in elongation to break was noted for the blended RSPU. This could be rationalised by agglomeration of the bis-urea additive $\mathbf{2}$ which results in a less homogeneous film and thus the polymers properties are dictated by those of SPU $\mathbf{1}$, gives rise to an increase in elongation compared to RSPU-15\% and reduction in overall mechanical properties.

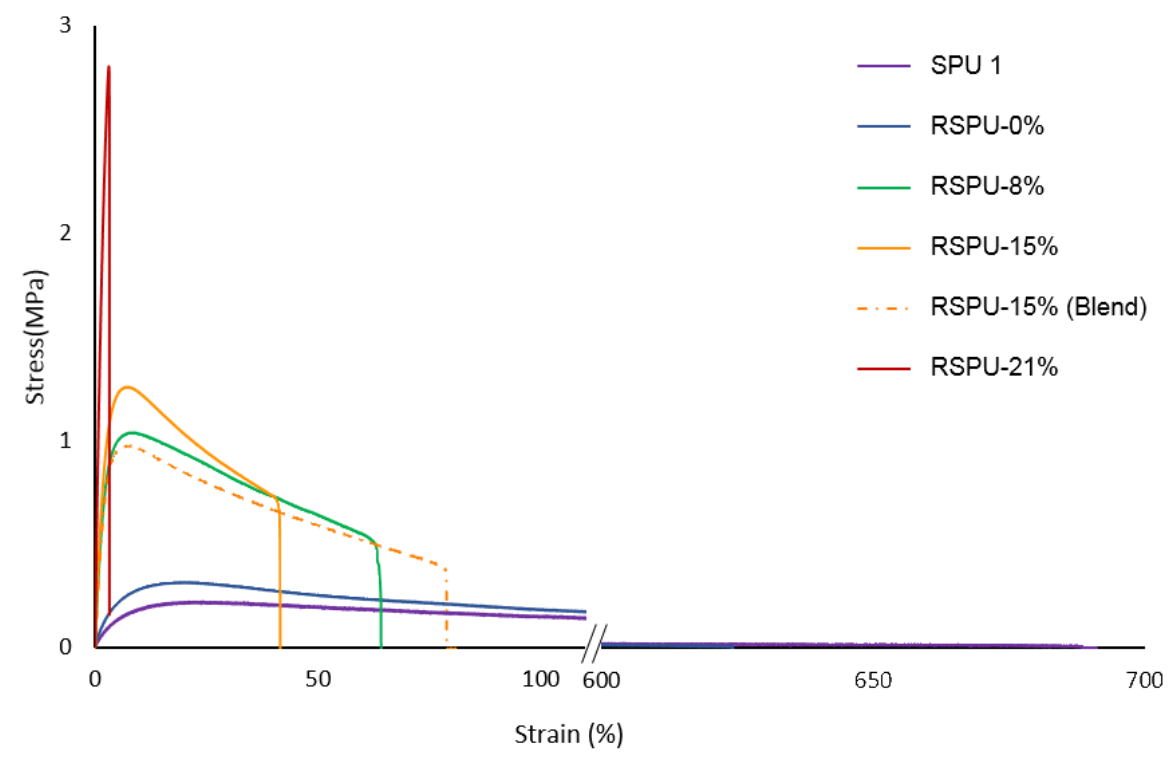

Figure 2: Stress-strain curves of the supramolecular polyurethane $\mathbf{1}$ and reinforced supramolecular polyurethanes RSPUs with increasing weight loading of the low molecular weight additive 2. 


\begin{tabular}{ccccc}
\hline Polyurethane & $\begin{array}{c}\text { Young's modulus } \\
(\mathbf{M P a})\end{array}$ & $\begin{array}{c}\text { Ultimate tensile } \\
\text { modulus }(\mathbf{M P a})\end{array}$ & $\begin{array}{c}\text { Toughness } \\
(\mathbf{M P a})\end{array}$ & $\begin{array}{c}\text { Strain at Break } \\
(\%)\end{array}$ \\
\hline SPU 1 & $3.9 \pm 1.4$ & $0.3 \pm 0.1$ & $0.6 \pm 0.1$ & $617 \pm 73.0$ \\
RSPU-0\% & $4.4 \pm 1.4$ & $0.3 \pm 0.0$ & $0.6 \pm 0.0$ & $608 \pm 16.0$ \\
RSPU-8\% & $36.8 \pm 4.2$ & $1.0 \pm 0.1$ & $0.4 \pm 0.1$ & $66 \pm 12.0$ \\
RSPU-15\% & $43.2 \pm 4.4$ & $1.4 \pm 0.1$ & $0.5 \pm 0.1$ & $46 \pm 8.0$ \\
RSPU-15\%-Blend & $35.4 \pm 1.7$ & $0.9 \pm 0.0$ & $0.4 \pm 0.1$ & $80 \pm 10.0$ \\
RSPU-21\% & $135.2 \pm 18.1$ & $2.5 \pm 0.3$ & $0.1 \pm 0.0$ & $3 \pm 1.0$ \\
\hline
\end{tabular}

Table 3: Mechanical properties of the SPU 1 and RSPUs (values shown are the average of 3 repeats).

To further assess the mechanical characteristics of the reinforced polyurethanes, rheological analysis (Figure 3) was undertaken to explore the viscoelastic elastic nature of the polymers and determine the effect of the LWMA on the thermally addressable materials. Temperature sweeps (Figure S23) were performed in oscillatory shear, revealing that the rubbery properties of the materials dominate in the low temperature regime $\left(0-40{ }^{\circ} \mathrm{C}\right)$. In this range, the characteristics of the supramolecular polymer is predominant, resulting in an elastomeric but stiff material, and is not affected by the incorporation of the bis-urea additive 1. Increasing the temperature further resulted in a decrease in the storage and loss modulus in all materials. The rate of change accelerating between $40{ }^{\circ} \mathrm{C}$ and $80{ }^{\circ} \mathrm{C}$ owing to the dissociation of the supramolecular interactions and the material properties are defined by the viscoelastic properties of the polymers at elevated temperatures. Increasing the weight percentage of 1 in the composite retards this effect and thus the material remains stiffer at elevated temperatures. The storage modulus, $\mathrm{G}^{\prime}$, decreased by no more than an order of magnitude in polyurethanes reinforced with more than $8 \mathrm{wt} \%$ LMWA, whereas a decrease of 3 orders of magnitude was observed in the pure supramolecular polymer and RSPU-0\%. In agreement with tensile testing, RSPU-21\% does not behave elastically under load and thus does not exhibit a significant loss in storage modulus over the temperature range.[45] These results correlate well with visual inspection of the materials when heated, in which RSPU-8\% and RSPU-15\% appear to soften slightly but retain their physical integrity at elevated temperatures, whereas RSPU-21\% remained stiff and brittle in nature over the same temperature regime and therefore was not able to be examined under comparable analytical conditions on the rheometer. This phenomenon can be attributed to the reduction in soft polymer content in the phase separated material, decreasing the flexible component of the polyurethane. Furthermore, the notable increase in storage modulus of the RSPUs is a clear indicator of increased hydrogen bonding interactions in the polymer network. 


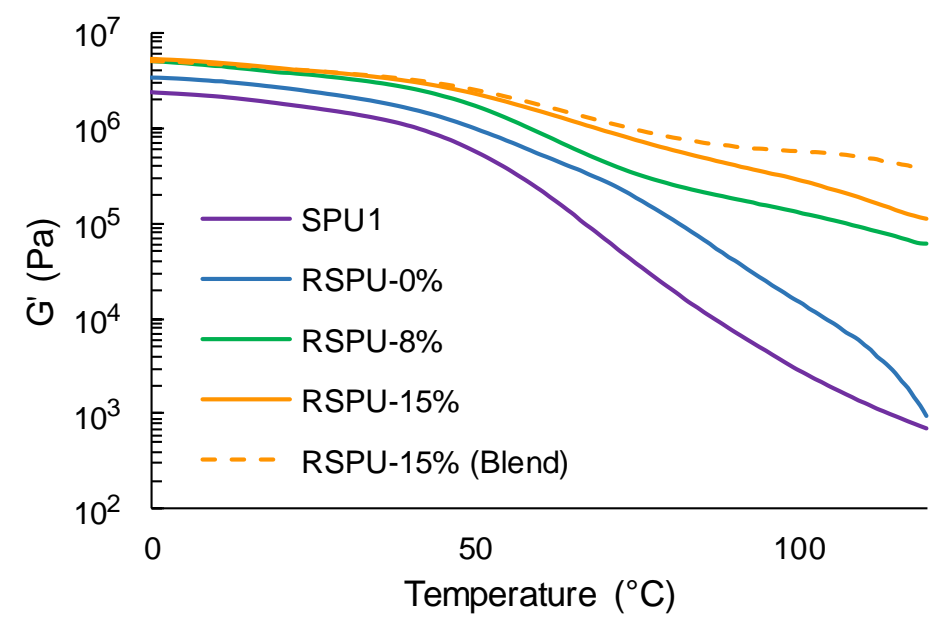

Figure 3: Changes in storage modulus $\left(\mathrm{G}^{\prime}\right)$ of the SPU 1 and RSPUs between 0 and $120^{\circ} \mathrm{C}$.

In order to further understand the morphology of the reinforced polymers, small angle X-ray scattering (SAXS) (Figure S24) and wide angle X-ray scattering (WAXS) (Figure S25) was employed. The WAXS scattering pattern revealed an amorphous halo with spacings centred around $4.9 \AA$ A suggesting the presence of stacked urea moieties within the supramolecular array. Crystalline features are seen to emerge, as evidenced by distinct signals which grow in intensity with respect to increased weight percentages of the LMWA 2. The SAXS scattering patterns for the supramolecular polyurethane $\mathbf{1}$ and reinforced polymers RSPUs formed in situ all showed a domain spacing of $66.1 \AA$, suggesting a microphase-separated morphology arising from the immiscibility of the hard hydrogen bonding endgroups with the soft polymer backbone. Crucially, the composite formulated by blending RSPU-15\% (Blend) revealed a domain spacing of $56.0 \AA$, indicating that a different assembly mode was present. This provides further evidence of aggregation between the LMWA 2 and a less homogeneous polymer network, indicating composite formulation is paramount.

To probe the thermal responsive nature of the supramolecular networks, variable temperature SAXS analysis was undertaken (Figure 4). Upon heating from $-60{ }^{\circ} \mathrm{C}$ to approximately $30{ }^{\circ} \mathrm{C}$, no significant change was observed in the morphology of the polymer composites. Increasing the temperature further resulted in a decrease in the domain spacing at $66.1 \AA$ RSPU-15\% and $56.0 \AA$ RSPU-15\% (Blend) respectively, caused by efficient phase mixing between the hard and soft domains. This is in good agreement with rheological data, which demonstrated a decrease in storage modulus at equivalent temperatures. On cooling the materials, microphase-separation is restored in the polymer network by reassociation of hydrogen bonding motifs. Similar trends were observed for all polyurethanes (Figure S26), demonstrating that the addition of the bis-urea additive $\mathbf{2}$ does not disrupt the thermal reversibility of the supramolecular polymers. Furthermore, variable temperature FT-IR spectroscopic analysis was conducted on the SPU 1 and RSPUs (Figure S27) and revealed a thermo-responsive behaviour similar 
to structurally related polyurethanes.[35,42,46,47] A strong absorbance for hydrogen bonded N-H absorbances was observed, centred at approximately $3320 \mathrm{~cm}^{-1}$, arising from urethane and urea moieties. The intensity of the absorbance band (calculated by integration between $3400-3100 \mathrm{~cm}^{-1}$ ) was seen to diminish with increased temperature $\left(20^{\circ} \mathrm{C}-120^{\circ} \mathrm{C}\right)$ for all polyurethanes as a result of dissociation of the hydrogen bonding interaction within the polymer network.
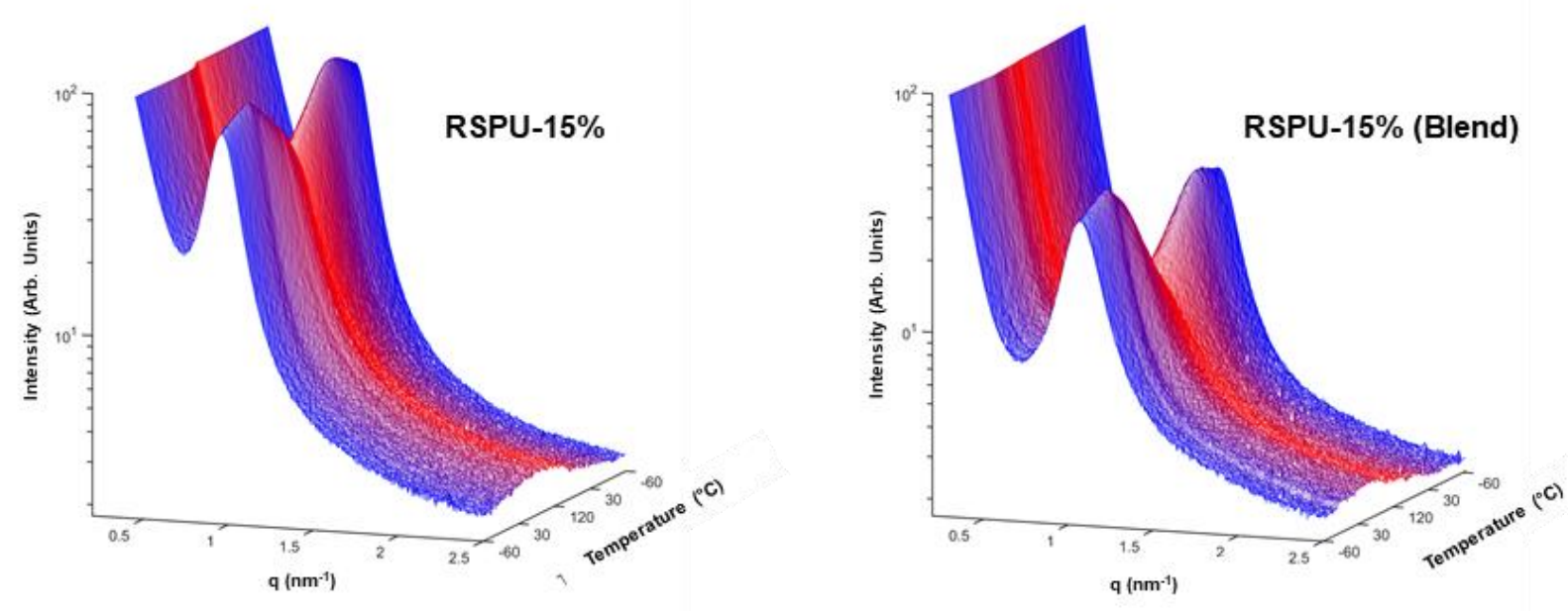

Figure 4: Variable temperature SAXS analysis of RSPU 15\% and RSPU 15\% (Blend).

Powder X-ray diffraction data provided further insight to the role of the LMWA in the polymer composites. The diffraction pattern of LMWA 2 was compared (Figure S28) to the polymer prepared in situ RSPU $15 \%$ and the formulation prepared by blending RSPU 15\% (Blend). It was apparent that the powder patterns for 2 and both RSPU 15\% and RSPU 15\% (Blend) shared many common diffraction peaks with the LMWA 2, suggesting that the additive was able to agglomerate into crystallites, however, the noticeable differences in reflection intensities attributable to LMWA 2 in both polymer samples suggest a marked difference in the distribution of crystallites in the two samples. Owing to the broad nature of the powder patterns of the polyurethanes, the crystalline phases were not able to be indexed. In addition, DSC data (Figure S20) confirm multiple polymorphs present in the LMWA 2, further complicating any attempts at indexing.

To further analyse the self-assembly of the SPU 1 and RSPUs, AFM studies (Figure 5 and Figure S29) were carried out to visualise the changes in the morphology attained by the addition of the LMWA 2 at increasing mole percentages and the effect of preparation in situ as opposed to blending. As expected, micro-phase separation was observed in SPU 1 (Figure S29) as a consequence of the assembly of hydrogen bonding motifs and the ordered stacking of the MDI linkers which promote the packing of both urethane and urea moieties. Interestingly, phase separation became more apparent with increased loading of LMWA 2, whilst remaining at the same length scale as supported by SAXS analysis (Figure 4 \& Figure S24). This increase in intensity also correlates well with both WAXS (Figure S25) 
and powder diffraction analysis (Figure S28), in which the diffraction signals increased in both dspacing and magnitude with increased content of LMWA 2. Furthermore, a correlation between the morphology observed in the AFM micrographs (Figure S29) and the ${ }^{1} \mathrm{H}$ NMR spectral data was noted. A shoulder was observed in the proton resonance at ca. $3.90 \mathrm{ppm}$ (Figure S21) attributed to the methylene bridge of the MDI residues in the LMWA 2. Thus, it is proposed that there is an optimum additive concentration that leads to an improvement in polymer toughness and increased uniformity in the phase separation. For example, in the case where a multiplet is observed at $3.90 \mathrm{ppm}$ (RSPU-8\%, and RSPU-15\% (Blend)), aggregation of the hard segments is apparent. However, when these two resonances are coincident (RSPU-15\%) an even phase separated morphology is observed. When comparing the RSPUs prepared in situ or blended, it is apparent that a homogeneous and defined phase separated morphology is present in both samples, however, RSPU-15\% (Blend) revealed additional aggregation of hard domains, presenting a similar topography to RSPU-8\%, which can be attributed to poor mixing and intercalation of the LMWA 2 into the polymer network and hydrogen bonding array.
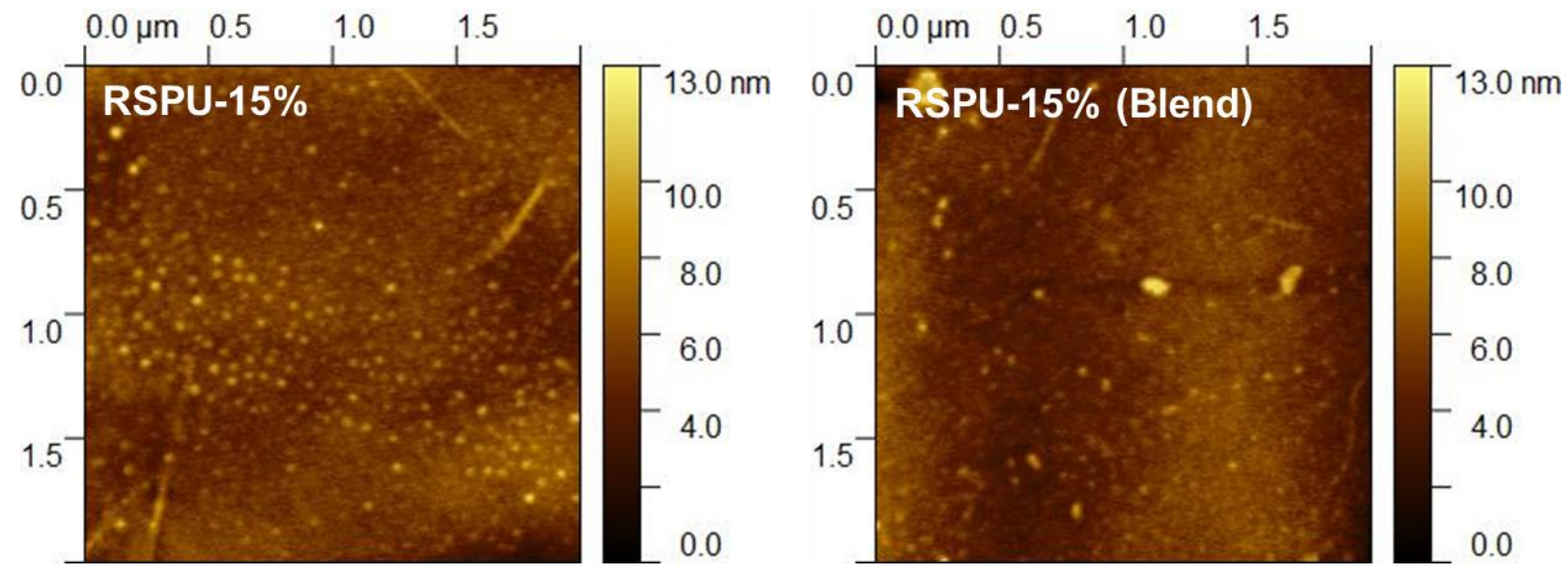

Figure 5: Topological AFM images of RSPU-15\% and RSPU-15\% (Blend).

Furthermore, analysis of the average diameters and distribution size of the hard domains for both RSPU-15\% and RSPU-15\% (Blend) within the micro-phase separated morphology demonstrated that the one-pot synthesis was able to better control the hard to soft domain ratio by reducing both the diameter $(30.4 \pm 0.4 \mathrm{~nm}, v s 58.4 \pm 1.4 \mathrm{~nm})$ and distribution size ( $45 \mathrm{~nm} v s .145 \mathrm{~nm}$ ) of the hard domain (Figures S30 and S31, Table S1). Therefore, the one-pot synthesis method ultimately provides a more homogenous and well-defined phase separated structure.

Our previous studies have shown that the neat supramolecular polyurethane $\mathbf{1}$ is healable[32] as a consequence of addressable and thermally responsive hydrogen bonding interactions. Therefore, the effect of the LMWA 2 on the healing properties of the polyurethanes were first assessed by variable temperature optical microscopy. Specimens of the polymer films were damaged using a scalpel blade, cutting thought the entire thickness of the film $(c a .1 \mathrm{~mm})$ and placed onto a glass slide. The damaged 
specimens were then heated at $10{ }^{\circ} \mathrm{C} \mathrm{min}^{-1}$ and healing assessed visually. As an exemplar, RSPU $15 \%$ and RSPU 15\% (Blend) (Figure 6) are seen to begin healing at approximately $60{ }^{\circ} \mathrm{C}$, and show complete closure of the damaged area at temperatures in excess of $90{ }^{\circ} \mathrm{C}$. All polymers, with the exception of RSPU 21\%, demonstrated optical healing in excess of 95\% (Figures S32). Indeed, the temperature required to induce healing increased with the increased weight percentage of bis-urea additive 2 from $40{ }^{\circ} \mathrm{C}$ in SPU 1 to $90{ }^{\circ} \mathrm{C}$ RSPU 15\%, as expected from rheological analysis of the materials.
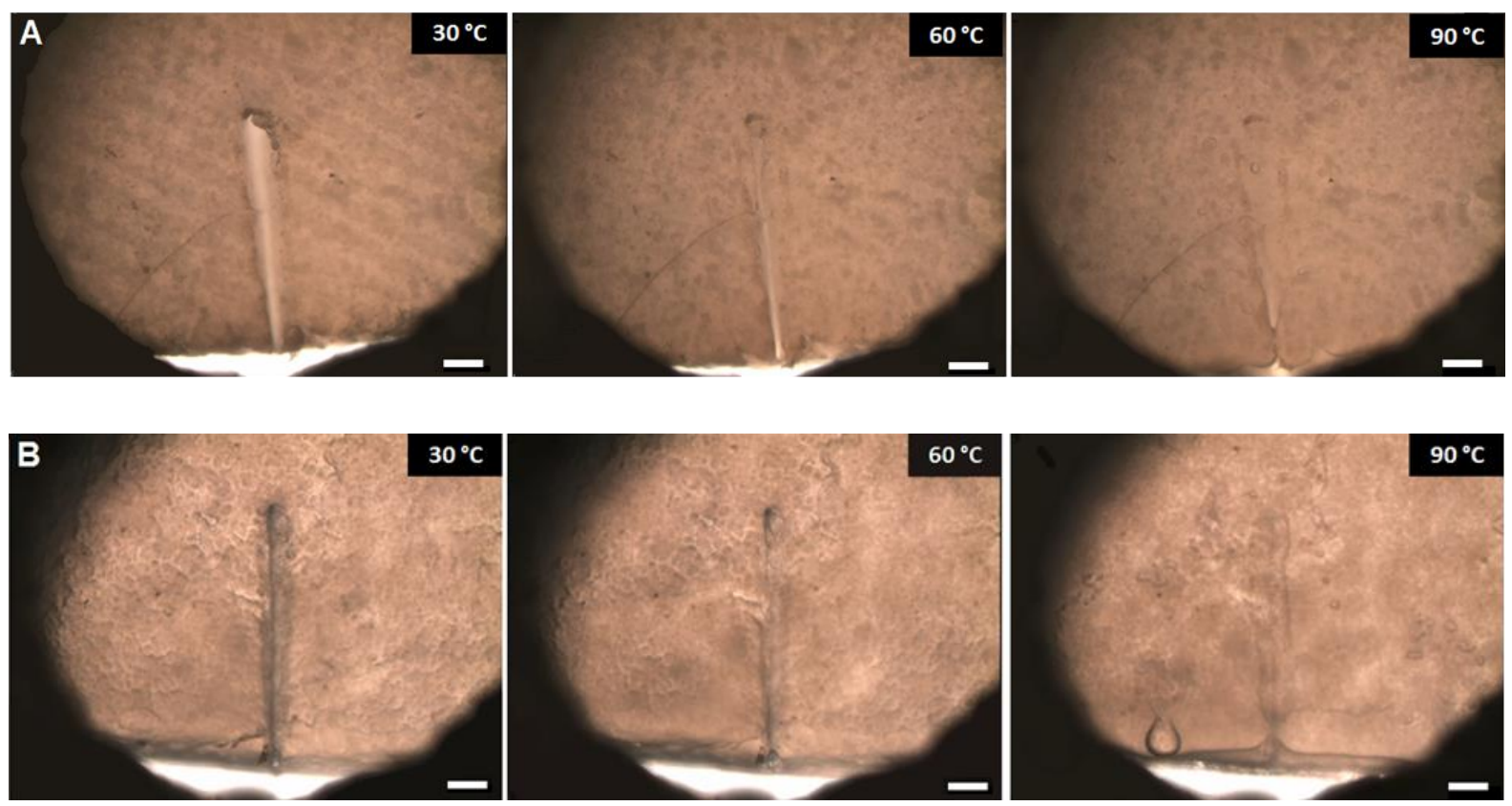

Figure 6: Progress of healing in A) RSPU $15 \%$ and B) P RSPU 15\% (Blend). Images were taken using an optical microscope equipped with a hot stage. The scale bar is representing $50 \mu \mathrm{m}$.

Finally, to examine the recovery of the mechanical properties after healing, tensile testing (Figure 7) was performed on polymer films cut into strips (dimensions $=40 \mathrm{~mm} \times 5 \mathrm{~mm} \times 1 \mathrm{~mm}$ ). The pristine polymer strips were cutting into two pieces and the damaged surfaced placed in contact with each other on a warmed PTFE plate. The stripes were placed into an oven for 1 hour at appropriate temperature derived from the rheological data and microscopy images for each polyurethane (Figures S23 and S32) before cooling to room temperature and carefully pealing from the PTFE plate. Promisingly, healing was observed in RSPU 15\% and RSPU 15\% (Blend). Healing efficiencies in excess of $98 \%$ with respect to Young's modulus are observed for both reinforced polymers; however, slight reductions in the ultimate tensile strength (RSPU 15\% $=77 \%$ recovery, RSPU 15\% (Blend) $=65 \%$ recovery) were apparent which is comparable to the pristine samples. Low healing efficiencies were seen in total amount of energy adsorbed (modulus of toughness, RSPU 15\% $=12 \%$ recovery, RSPU $15 \%$ (Blend) $=9 \%$ recovery) as a result in diminished elongations to break reducing the integration of the stress/strain curves. Similar trends were observed for all RSPUs (Figures S33-S35) revealing excellent 
recovery of the Young's modulus, moderate recovery of the ultimate tensile strength, and low healing efficiencies in modulus of toughness (Table S2). This reduction in modulus of toughness when healed is in keeping with data reported for other supramolecular polymers which exhibit healability.[3,4]

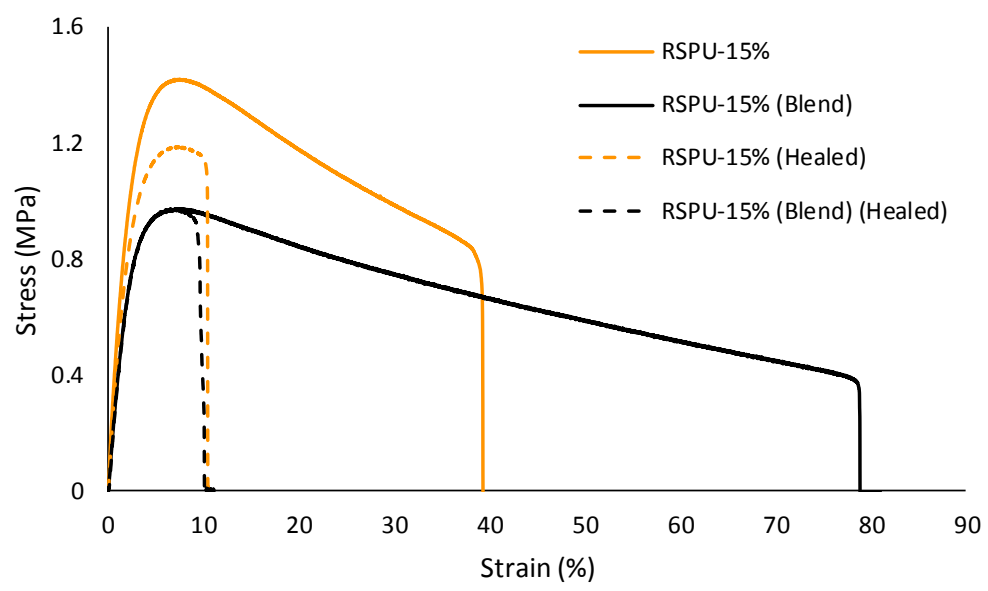

Figure 7: Tensile data for polymer composites RSPU 15\% and RSPU 15\% (Blend) showing their properties pre- and post-healing.

When comparing these data to the healability of the supramolecular polyurethane 1[32] which demonstrated complete recovery of ultimate tensile strength, Young's modulus and elongation at break, it is evident that healing efficiency is reduced though the addition of additives to the supramolecular polymer network. However, despite the reduction in healing efficiency, the utilisation of this synthetic approach in industrial applications may provide a facile route to increasing the mechanical performance of functional supramolecular polymers.

\section{Conclusions}

The mechanical strength of an industrially relevant supramolecular polyurethane has been enhanced using low molecular weight additives. Using a facile and accessible methodology, the bis-urea additive 2 was synthesised in situ and can cooperatively self-assemble with the thermally addressable supramolecular network via complementary hydrogen bonding interactions. Moreover, the polymers can be prepared without the need for complex purification or blending. By the addition of as little as $8 \mathrm{wt} \%$ of the LMWA, a significant increase in both the Young's modulus and ultimate tensile strength is achieved, $840 \%$ and $230 \%$, respectively, when compared to the phase separated polyurethane 1 alone in addition to retention of the modulus of toughness. Furthermore, increasing the loading of the additive continues to improve these properties up to a loading of $15 \mathrm{wt} \%$. Additionally, additive loadings of $21 \mathrm{wt} \%$ gave rise to an increasingly stiff but brittle material which was difficult to handle. A formulation comprising of the additive $(15 \mathrm{wt} \%)$ blended with the neat polyurethane was also 
produced to examine the effect of material preparation and filler dispersion within the polymer matrix. The mechanical performance of the reinforced polyurethane formulated by blending was diminished when compared to the analogous polymer generated in situ. Finally, the effect of the LMWA on the healability of the reinforced polyurethanes was examined. Healing was observed in reinforced polyurethanes with up to $15 \mathrm{wt} \%$ additive loading, with healing efficiencies in excess of $98 \%$ observed in the case of the Young's modulus. These findings demonstrate a facile, one-pot, purification-less methodology to produce industrially relevant supramolecular polyurethanes with improved physical and mechanical properties when compared to the pristine polymer alone. Further development and refinement of polymer blends of this type are required to produce materials which have desirable mechanical properties for real-world applications.

\section{Declaration of Interest}

The authors declare that there are no conflicts of interest.

\section{Acknowledgements}

The authors would like to acknowledge funding from the EPSRC (EP/N024818/1) and (EP/J011436/1) in support of a postdoctoral fellowships for LRH, ABRT and AF. Additionally, we acknowledge the University of Reading (ref GS17-025) for postgraduate studentship in support of SS. Prof. Clive Siviour and Dr Marzena Tkaczyk (Department of Engineering Science, the University of Oxford) are acknowledge for access to rheological facilities. The authors would also like to thank Cray Valley for the supply of Krasol HLBH-P2000, the University of Reading for access to analytical instrumentation within the Chemical Analysis Facility, Mr Nicolas Michael for his expertise in mass spectrometry, Miss Annabelle Black for her contributions in support of the research and Dr Barnaby Greenland for useful discussions relating to polyurethanes. Finally, Dr Oliver Balmford is also thanked for his insight in reproducing scattering data.

\section{Appendix A. Supplementary Information}

Supplementary data to this article can be found online at https://doi.org/10.1016/j.eurpolymj.2019

\section{References}

[1] J.W. Steed, J.L. Atwood, Supramolecular Chemistry, 2nd Edn., John Wiley \& Sons Ltd, Chichester, 2009. doi:10.1002/anie.198800891. 
[2] L. Brunsveld, B.J.B. Folmer, E.W. Meijer, R.P. Sijbesma, Supramolecular polymers., Chem. Rev. 101 (2001) 4071-4098. doi:10.1021/cr990125q.

[3] S. Burattini, B.W. Greenland, D. Chappell, H.M. Colquhoun, W. Hayes, Healable polymeric materials: a tutorial review., Chem. Soc. Rev. 39 (2010) 1973-1985. doi:10.1039/b904502n.

[4] L.R. Hart, J.L. Harries, B.W. Greenland, H.M. Colquhoun, W. Hayes, Healable supramolecular polymers, Polym. Chem. 4 (2013) 4860-4870. doi:10.1039/c3py00081h.

[5] S. Burattini, H.M. Colquhoun, B.W. Greenland, W. Hayes, Self-Healing and Mendable Supramolecular Polymers, in: P. Gale, J. Steed (Eds.), Supramol. Chem. From Mol. to Nanomater., John Wiley \& Sons Ltd., 2012. doi:10.1002/9780470661345.smc134.

[6] F. Herbst, D. Döhler, P. Michael, W.H. Binder, Self-healing polymers via supramolecular forces., Macromol. Rapid Commun. 34 (2013) 203-220. doi:10.1002/marc.201200675.

[7] J. Li, C.L. Lewis, D.L. Chen, M. Anthamatten, Dynamic mechanical behavior of photo-crosslinked shape-memory elastomers, Macromolecules. 44 (2011) 5336-5343. doi:10.1021/ma2004019.

[8] C. Heinzmann, S. Coulibaly, A. Roulin, G.L. Fiore, C. Weder, Light-induced bonding and debonding with supramolecular adhesives, ACS Appl. Mater. Interfaces. 6 (2014) 4713-4719. doi:10.1021/am405302z.

[9] M.W. Urban, Stratification, stimuli-responsiveness, self-healing, and signaling in polymer networks, Prog. Polym. Sci. 34 (2009) 679-687. doi:10.1016/j.progpolymsci.2009.03.004.

[10] J. Li, J.A. Viveros, M.H. Wrue, M. Anthamatten, Shape-Memory Effects in Polymer Networks Containing Reversibly Associating Side-Groups, Adv. Mater. 19 (2007) 2851-2855. doi:10.1002/adma.200602260.

[11] S. Meer, A. Kausar, T. Iqbal, Attributes of Polymer and Silica Nanoparticle Composites: A Review, Polym. Plast. Technol. Eng. 55 (2016) 826-861. doi:10.1080/03602559.2015.1103267.

[12] H. Zheng, J. Zhang, S. Lu, G. Wang, Z. Xu, Effect of core-shell composite particles on the sintering behavior and properties of nano-Al2O3/polystyrene composite prepared by SLS, Mater. Lett. 60 (2006) 1219-1223. doi:10.1016/j.matlet.2005.11.003.

[13] L. Jin, H. Wang, Y. Yang, Polyurethane composites in situ molecularly reinforced by supramolecular nanofibrillar aggregates of sorbitol derivatives, Compos. Sci. Technol. 79 (2013) 58-63. doi:10.1016/j.compscitech.2013.02.017.

[14] Y. Wang, J. Niu, J. Hou, Z. Wang, J. Wu, G. Meng, Z. Liu, X. Guo, A novel design strategy for triple-network structure hydrogels with high-strength, tough and self-healing properties, Polymer (Guildf). 135 (2018) 16-24. doi:10.1002/adfm.201404357.

[15] S. Hackelbusch, T. Rossow, P. Van Assenbergh, S. Seiffert, Chain Dynamics in Supramolecular Polymer Networks, Macromol. Symp. 46 (2013) 6273-6286. doi:DOI: $10.1021 / \mathrm{ma} 4003648$.

[16] P. Katti, K. V. Kundan, S. Kumar, S. Bose, Improved mechanical properties through engineering the interface by poly (ether ether ketone) grafted graphene oxide in epoxy based nanocomposites, Polymer (Guildf). 122 (2017) 184-193. doi:10.1016/j.polymer.2017.06.059.

[17] J. Fox, J.J. Wie, B.W. Greenland, S. Burattini, W. Hayes, H.M. Colquhoun, M.E. Mackay, S.J. Rowan, High-Strength, Healable, Supramolecular Polymer Nanocomposites, J. Am. Chem. Soc. 134 (2012) 5362-5368. doi:10.1021/ja300050x.

[18] F. Lin, R. Wang, L. Liu, B. Li, L.W. Ouyang, W.J. Liu, Enhanced intermolecular forces in supramolecular polymer nanocomposites, Express Polym. Lett. 11 (2017) 690-703. 
doi:10.3144/expresspolymlett.2017.67.

[19] V. Kostopoulos, A. Kotrotsos, S. Tsantzalis, P. Tsokanas, T. Loutas, A.W. Bosman, Toughening and healing of continuous fibre reinforced composites by supramolecular polymers, Compos. Sci. Technol. 128 (2016) 84-93. doi:10.1016/j.compscitech.2016.03.021.

[20] V. Kostopoulos, A. Kotrotsos, A. Baltopoulos, S. Tsantzalis, P. Tsokanas, T. Loutas, A.W. Bosman, Mode II fracture toughening and healing of composites using supramolecular polymer interlayers, Express Polym. Lett. 10 (2016) 914-926. doi:10.3144/expresspolymlett.2016.85.

[21] X. Tan, Y. Zhao, M. Shang, G.R. Hamed, L. Jia, Supramolecular reinforcement of styrenebutadiene rubber composites, Polymer (Guildf). 122 (2017) 242-248. doi:10.1016/j.polymer.2017.06.056.

[22] P. Shokrollahi, H. Mirzadeh, O.A. Scherman, W.T.S. Huck, Biological and mechanical properties of novel composites based on supramolecular polycaprolactone and functionalized hydroxyapatite, J. Biomed. Mater. Res. - Part A. 95 (2010) 209-221. doi:10.1002/jbm.a.32828.

[23] R. Vaiyapuri, B.W. Greenland, H.M. Colquhoun, J.M. Elliott, W. Hayes, Molecular recognition between functionalized gold nanoparticles and healable, supramolecular polymer blends - a route to property enhancement, Polym. Chem. 4 (2013) 4902-4909. doi:10.1039/c3py00086a.

[24] B.C. Baker, I. German, G.C. Stevens, H.M. Colquhoun, W. Hayes, Inducing hardening and healability in poly(ethylene-co acrylic acid) via blending with complementary low molecular weight additives, RSC Adv. 8 (2018) 41445-41453. doi:10.1039/C8RA09597C.

[25] D.J. Cornwell, D.K. Smith, Expanding the scope of gels - Combining polymers with lowmolecular-weight gelators to yield modified self-assembling smart materials with high-tech applications, Mater. Horizons. 2 (2015) 279-293. doi:10.1039/c4mh00245h.

[26] T.F.A. De Greef, M.M.L. Nieuwenhuizen, R.P. Sijbesma, E.W. Meijer, Competitive intramolecular hydrogen bonding in oligo(ethylene oxide) substituted quadruple hydrogen bonded systems, J. Org. Chem. 75 (2010) 598-610. doi:10.1021/jo902053t.

[27] B.C. Baker, I.M. German, A.M. Chippindale, C.E.A. McEwan, G.C. Stevens, H.M. Colquhoun, W. Hayes, Nitroarylurea-terminated supramolecular polymers that exhibit facile thermal repair and aqueous swelling-induced sealing of defects, Polymer (Guildf). 140 (2018) 1-9. doi:10.1016/j.polymer.2018.02.029.

[28] B.C. Baker, C.L. Higgins, D. Ravishankar, H.M. Colquhoun, G.C. Stevens, F. Greco, B.W. Greenland, W. Hayes, Multifunctional, Biocompatible, Non-peptidic Hydrogels: from Water Purification to Drug Delivery, ChemistrySelect. 1 (2016) 1641-1649. doi:10.1002/slct.201600249.

[29] B.C. Baker, A.L. Acton, G.C. Stevens, W. Hayes, Bis amide-aromatic-ureas - Highly effective hydro- and organogelator systems, Tetrahedron. 70 (2014) 8303-8311. doi:10.1016/j.tet.2014.09.017.

[30] D.M. Wood, B.W. Greenland, A.L. Acton, F. Rodriguez-Llansola, C.A. Murray, C.J. Cardin, J.F. Miravet, B. Escuder, I.W. Hamley, W. Hayes, pH-Tunable hydrogelators for water purification: structural optimisation and evaluation., Chem. - A Eur. J. 18 (2012) 2692-2699. doi:10.1002/chem.201102137.

[31] F. Rodriguez-Llansola, B. Escuder, J.F. Miravet, D. Hermida-Merino, I.W. Hamley, C.J. Cardin, W. Hayes, Selective and highly efficient dye scavenging by a $\mathrm{pH}$-responsive molecular hydrogelator, Chem. Commun. 46 (2010) 7960-7962. doi:10.1039/c0cc02338h.

[32] A. Feula, X. Tang, I. Giannakopoulos, A.M. Chippindale, I.W. Hamley, F. Greco, C.P. 
Buckley, C.R. Siviour, W. Hayes, C. Paul Buckley, C.R. Siviour, W. Hayes, An adhesive elastomeric supramolecular polyurethane healable at body temperature, Chem. Sci. 7 (2016) 4291-4300. doi:10.1039/C5SC04864H.

[33] I. Yilgör, E. Yilgör, G.L. Wilkes, Critical parameters in designing segmented polyurethanes and their effect on morphology and properties: A comprehensive review, Polymer (Guildf). 58 (2015) A1-A36. doi:10.1016/j.polymer.2014.12.014.

[34] I. Yilgor, E. Yilgor, Structure-morphology-property behavior of segmented thermoplastic polyurethanes and polyureas prepared without chain extenders, Polym. Rev. 47 (2007) 487510. doi:10.1080/15583720701638260.

[35] D. Hermida-Merino, B.O. Driscoll, L.R. Hart, P.J. Harris, H.M. Colquhoun, A.T. Slark, C. Prisacariu, I.W. Hamley, W. Hayes, Enhancement of microphase ordering and mechanical properties of supramolecular hydrogen-bonded polyurethane networks, Polym. Chem. 9 (2018) 3406-3414. doi:10.1039/c8py00604k.

[36] C. Prisacariu, E. Scortanu, I. Stoica, B. Agapie, V. Barboiu, Morphological features and thermal and mechanical response in segmented polyurethane elastomers based on mixtures of isocyanates, Polym. J. 43 (2011) 613-620. doi:10.1038/pj.2011.23.

[37] R.M. Versteegen, R.P. Sijbesma, E.W. Meijer, Synthesis and characterization of segmented copoly(ether urea)s with uniform hard segments, Macromolecules. 38 (2005) 3176-3184. doi:10.1021/ma0478207.

[38] K.A. Houton, A.J. Wilson, Hydrogen-bonded supramolecular polyurethanes, Polym. Int. 64 (2015) 165-173. doi:10.1002/pi.4837.

[39] A.J. Wilson, Non-covalent polymer assembly using arrays of hydrogen-bonds, Soft Matter. 3 (2007) 409-425. doi:10.1039/b612566b.

[40] S. Sivakova, D.A. Bohnsack, M.E. Mackay, P. Suwanmala, S.J. Rowan, Utilization of a combination of weak hydrogen-bonding interactions and phase segregation to yield highly thermosensitive supramolecular polymers., J. Am. Chem. Soc. 127 (2005) 18202-18211. doi:10.1021/ja055245w.

[41] P. Woodward, A. Clarke, B.W. Greenland, D. Hermida-Merino, L. Yates, A.T. Slark, J.F. Miravet, W. Hayes, D.H. Merino, Facile bisurethane supramolecular polymers containing flexible alicyclic receptor units, Soft Matter. 5 (2009) 2000-2010. doi:10.1039/b817094k.

[42] D. Hermida-Merino, A. Feula, K. Melia, A.T. Slark, I. Giannakopoulos, C.R. Siviour, C.P. Buckley, B.W. Greenland, D. Liu, Y. Gan, P.J. Harris, A.M. Chippindale, I.W. Hamley, W. Hayes, A systematic study of the effect of the hard end-group composition on the microphase separation, thermal and mechanical properties of supramolecular polyurethanes, Polymer (Guildf). 107 (2016) 368-378. doi:10.1016/j.polymer.2016.07.029.

[43] V. Simic, L. Bouteiller, M. Jalabert, Highly Cooperative Formation of Bis-Urea Based Supramolecular Polymers, J. Am. Chem. Soc. 125 (2003) 13148-13154. doi:10.1021/ja037589x.

[44] S. Iqbal, F. Rodríguez-Llansola, B. Escuder, J.F. Miravet, I. Verbruggen, R. Willem, HRMAS 1H NMR as a tool for the study of supramolecular gels, Soft Matter. 6 (2010) 1875-1878. doi:10.1039/b926785a.

[45] H. Kautz, D.J.M. Van Beek, R.P. Sijbesma, E.W. Meijer, Cooperative end-to-end and lateral hydrogen-bonding motifs in supramolecular thermoplastic elastomers, Macromolecules. 39 (2006) 4265-4267. doi:10.1021/ma060706z.

[46] P. Woodward, D.H. Merino, B.W. Greenland, I.W. Hamley, Z. Light, A.T. Slark, W. Hayes, D. Hermida-Merino, Hydrogen Bonded Supramolecular Elastomers: Correlating Hydrogen 
Bonding Strength with Morphology and Rheology, Macromolecules. 43 (2010) 2512-2517. doi:10.1021/ma9027646.

[47] S. Burattini, D.H. Merino, W. Weng, J. Seppala, H.M. Colquhoun, W. Hayes, M.E. Mackay, I.W. Hamley, S.J. Rowan, A Healable Supramolecular Polymer Blend Based on Aromatic $\pi$ $\pi$ Stacking and Hydrogen-Bonding Interactions, (2010) 12051-12058. doi:10.1021/ja104446r. 